\begin{tabular}{|c|c|}
\hline & Volume \& Issues Obtainable at The Women University Multan \\
Annals of Social Sciences and Perspective \\
ISSN: 2707-7063, Volume 2, No.2 December 2021
\end{tabular}

\title{
Organization Culture Change and its Effect on Women's Motivation
}

\author{
Zeeshan Rasool ${ }^{1}$, Rabail Shoukat ${ }^{2}$
}

${ }^{1}$ School of Economics and Management, Shaanxi University of Science and Technology, Xi'an 710021, China

${ }^{2}$ Management Science Department, Bahria University Karachi Campus, Pakistan

\section{ARTICLE DETAILS ABSTRACT}

\section{History:}

Received:

Review:

Accepted:

October 21,2021

November 22, 2021

\section{Keywords:}

Organizational Culture; Women's

Motivation; Organizational

Planning; Strategy Development

\section{DOI:}

10.52700/assap.v2i2.84
The research study is mainly about the organization's culture change and its effect on women's motivation in the organization. The selected organization for this research is $K$-Electric and the study focuses on the transition and transformation in the organizational context. The objectives have been developed to identify and investigate that how cultural change can affect motivation. In this regard, a review of literature has been done to conduct the secondary analysis, however, for primary analysis, semi-structured interviews have been conducted and a close-ended questionnaire has been developed on Likert scale to obtain quantitative nature of data, to further analyze it by applying the quantitative tools and methods in particular. The main findings of the overall research are that the organizational culture change in K-Electric has a direct and profound impact on the women's level of motivation. Moreover, programs that were undertaken to motivate the women's also resulted in women's increased level of adaptability and flexibility in the organization to a greater extent. The research limitation and future implications have also been discussed in the research. Along with this, the conclusion of the overall study has been given; in addition to the recommendations to further bring improvements in the organizational planning and formulated strategies.

(C) 2021 The Authors, Published by WUM. This is an Open Access Article under the Creative Common Attribution Non Commercial 4.0

Corresponding author's email address: zeeshan rasool114@hotmail.com

\section{Introduction}

Every business entity strives to ensure its existence and presence in the market along with maintaining its prosperity. The high level of competition has sent the management of organizations, no matter how small, big or multinational they are, to struggle for women's 
retention. To make sure that women remain loyal to the company, employers need to form a strong bond with the women, which is conceivable only when the women are contended and continuously motivated to work. Organizations have accepted the significance of loyal and effective women's which was not regarded as imperative by big multinationals until only recently. Organizational change is a professionally driven intercession arranged way to deal with effecting authoritative change using individual change, with perspective to expanding viability [. According to, commitment-based methods of effecting change except that the catalyst for change must originate from the base up, whilst consistency based techniques include the production of behavioral objectives for change. Motivation can be understood from two perspectives; women and employers. Motivation from the perspective of the employer can be seen as a mechanism that employers use to motivate workers into improved results and precocity. On the other hand motivation from the women's end can be implied as to the pulling forces or those factors that pull women towards themselves for which women strive and perform better to attain that reward which acted as the motivating factor.

Individuals can recognize the organizations to internalize the behavior codes and the interest of others. It is significant to be familiar with an organization where women's by the organizational culture can be guaranteed that they can pursue the objectives and goals of the organization. According to, the culture of the organization has been invented with its issues of internal integration and external adaptation.

\subsection{Research Aims}

Since the electric companies have experienced a high level of turnover when observed overall, such a company has been chosen for this study which has been able to retain its women to a larger extent, K-electric. K-electric has been selected to be studied for solving this problem of the research because K-electric has managed to retain its women's and the success of the company is not unknown to the world. Therefore, the core aim of the research is to solve the problem in the light of K-Electric which has been formulated as;

"To find out the role of organizational culture and motivated women towards the success of K-Electric in Pakistan".

\subsection{Research Objectives}

The research intends to attain the following objectives;

- To assess the extent to which women's attitudes towards work change when they are satisfied.

- To identify how organizational culture change could influence women's motivation for K-Electric.

- To investigate the key motivating factors for the women of K-Electric.

- To review the role of motivated women towards the success of K-electric.

\subsection{Significance of the Study}

The research aims to analyze the motivational methods and causes, as it recognizes the impact it has on businesses and the evolving nature of electrical organizations in their respective sectors. This helps to complete the report, as it discusses the organizations' further involvement with respect to the motivations of their workers and they can further develop the 
approaches they endorse further in managing the company's human capital. The key advantage of this study is that the HR department gives the company's workers the most inspiring and rewarding climate.

\subsection{Rationale of the Study}

The war between companies was not confined to consumers, market share, and marketing but also broadened its horizons and became part of the human resources field. Women and their expertise are now regarded by organizations as essential assets. Previously, only technology or patents were seen as a competitive advantage, but the equal value of human capital is now given to the success of the business. Considering that women's are expected to contribute to performance and competitive advantage, it is important to understand whether this is true only when women's are sustained or when the women's are not happy or even when they have equal efficiency, thus research and conduct on an organization with both achievements and motivation are important.

\section{Literature Review}

The culture, norms, rules, and regulations of a company do not remain the same through the years. They are bound to change with changes in society, advancements, technological revolutions etcetera. Any firm that fails to match pace with these changing trends remains left behind in the advancement towards growth and success (Abonam, 2011). Changes occur in many dimensions. Sometimes the company changes its entire workforce to bring in more competent and skilled workers, sometimes a company goes under a technological revolution where the old technologies and ways of doing operations become obsolete and are replaced by new methods and techniques (Adkins, 2004). Sometimes a company changes its operations by expanding into new markets or stepping into new areas of operation, but sometimes the change is more implicit and critical. Sometimes companies need to change their culture and it is one of the toughest challenges faced by a firm in its actions (Hartnell and Kinicki, 2011). To adapt themselves better to the changing marketplace needs and consumer tastes and preferences, organizations often go through major changes in terms of culture, structure, and strategic direction and these changes have a profound effect on women's and their motivational levels (Anderson and Anderson, 2001). To make certain that the objectives of change are correctly met, the management must ensure that the change is internalized, women are guided and assisted through the change process and any issues that they come across during the process are promptly addressed by the management. This is how the women experience the positivity and benefits of the change. In this connection, a number of scholars and academicians have presented theories concerning the organizational culture changes and their impact on the performance, efficiency and commitment of women. The cultural archetype consists of and incorporates various morals, values, traditions and systems that not only overlook the operations of the firm but are also reflected in the conduct, behavior and demeanor of every individual (Black, 2003). Culture is the language that every person speaks, no matter how they behave outside the company; their actions comply with the standard set by the management as they step inside their workplace. It is that governing principle that can be seen in the conduct of every person involved in the company ranging from the chief executive officer to the front line managers. Not only that, but a company's culture is also a key determinant in choosing its suppliers, creditors, and stakeholders. It is because of this reason, the vitality organizational culture holds in any company's functions, that in case of an acquisition, merger, or change in the company, the most difficult women's 
face is changing their old patterns of behaviors and adapting to the new culture (Fullan, 2011).

One of the factors concerning the organizational culture change and its subsequent influence on women's motivation relates to the women's involvement in the organizational decision making and strategic direction. It is the basic human nature, according to several observers, to belong to and be involved intricately with their organizational culture, future and strategic path. If women are made to work with little involvement in the organizational culture and there is little interaction between various functions and departments, then their motivational levels will naturally drop and there will be little commitment and loyalty to the company's goals and objectives. When women feel more involved and valued, they will naturally be more inclined towards achieving the organizational goals and targets, and hence their motivational level and performance will witness improvement (Epstein and Buhovac, 2014). Therefore, making changes in the decision process and flow of information among women's ranging from senior executives to middle managers and front line workers and involving them in making a decision when and where it is necessary can create a sense of ownership among them regarding their organization, management and its functions (Dysvik and Kuvaas, 2010). They would feel important by the fact that their input has been taken into account; it has been considered and pondered upon. Organizations, where women are just imposed with orders and decisions that are made by the senior management behind closed doors, have an adverse effect not only on women's motivation and productivity but also on the overall climate of the company. They begin hoarding ill feelings towards the upper management and it ultimately leads to conflicts and lower productivity. . Therefore, Engaging relevant women's in the decision making process and inviting them to monthly meets with other departments of the company so that they don't feel isolated in their respective departments but get to see the overall progress of the company, changes in its creative approaches, a chance to meet other people and a possibility to voice their ideas and have a say in the emerging creative strategies (Robbins, 2013).

Cultural changes can be brought into the functions and processes of the organization in many ways. One of the most effective and productive manners of bringing change is creating a leadership environment in the company where every woman is guided and motivated to become a leader. To assist this aim, role plays and various group activities should be conducted to engage women in leadership roles where they can manage teams, make decisions, resolve issues and lead from the front. These activities would create a culture for winners where everyone tries to be a better leader and mentor than the other and ultimately the whole organization would be guided towards success and excellence.

In this respect, an organization's culture brings together and binds the women to common goals and objectives, seeking growth and success for both. The management must ensure that the culture aligns with the vision and mission of the company and whether women can relate to it or not. If women do not find the significance of logic in the cultural changes or alterations projected by the upper management or human resource department, their motivation to comply with those changes and the urge to ace and excel in the change would diminish. They would consider it as just another unworthy and insignificant ritual they can get away with. Introduction of policies, values, practices and activities that boost up the morale of workers, help them remain motivated and give them a sense of belonging to the organization have exceptional effects on their performance, loyalty and productivity. Therefore, an organizational culture contributes to women's motivation by involving a common set of shared assumptions and practices that help develop a code of conduct, an 
internal integration process of assimilation and cooperation and women's involvement and well-being. It cannot be denied that happy women make a happy workplace. Women are not just the human capital appointed for mounting sales and maximizing profits but they need to remain satisfied and motivated. They are considered as one of the most important assets of the organization that must be properly equipped with necessary instructions, training, tools for increased productivity and resources. Organizations today are now aligning their objects and strategies to match a women's-oriented organization by creating a sense of belonging among their workforce through diverse methods like workshops, seminars, training sessions, site visits and various other women's engagement activities.

To achieve this objective, the company can provide them with learning prospects (Judge et al., 2002). The company can arrange different programs and seminars for its women that can assist their learning in their respective professional fields so that it doesn't only reflect positively upon their productivity but also facilitate them to ascend the competency ladder. By gaining experience and education regarding their respective fields and area of expertise, women's become more valuable in the industry and market.

A well-trained manager can play a substantial role when it comes to urging women to work at their best potential. Through proper coaching, a manager can also become a great mentor who not only leads his team in the right direction but he also creates a bond of trust, empathy and companionship with his women. Titles like "Women's of the Month" in the company's newsletter can boost confidence and there are numerous other ways to promote productive behavior like selecting the best performer of the month and providing that individual with certain benefits and compensations. High performers can also be made the head of their teams and indulge in leadership roles as a result of their performance. Women are the bread and butter of any organization; they are the tools of marketing that have direct contact with the general public. What they experience and observe in the organization is traveled to the general public where general conceptions and views spur regarding the company's reputation and well being. By investing in women's activities companies are not only enhancing their confidence and efficiency but are also investing in their improved image and standing in the corporate world since every woman is an ambassador of the firm (Phillips, 1983).

Efforts were undertaken to boast women's performance and motivation reflect on the company's success not only in terms of greater sales, lesser turnover, reduced absenteeism, better profit margins, greater market share but it also reflects in the attitude of women's as they are more loyal, motivated, satisfied, and productive and above all, happier. When women's share a common set of goals, a culture that nurtures their capabilities and skills, a culture that promotes individual capabilities, leadership roles and involvement in company's processes and activities, management that assists them in reaching their goals and an aim that results in achieving better professional performance than such organizations become the epitome of victory, unity and excellence where everyone strives for the best and this combined urge for brilliance and distinction and this drive ultimately guides the company towards the accomplishment of its goals, objectives, mission and vision (Hartog et al., 2004).

Corporate culture, regardless of a certain type or kind, is effective because it is known to bring order, stability and consistency to the organization. A unified corporate or organizational culture is hence necessary not only for the very survival and competitiveness of the business entity, but it is also essential for shaping the work attitudes and women's performance, which ultimately leads to higher job satisfaction and enhanced women's 
motivation. On the other hand, corporate culture cannot endure for very long if it does not absorb necessary changes and adaptations about marketplace changes, shifts in consumer preferences and tastes as well as the economic conditions prevailing in the country or region. The dynamic commercial markets today dictate constant change at the workplace, which means the whole organizational system must respond in affirmative to the continuously changing and transforming business environment.

Once accepting and establishing change at the workplace, it is now the duty and responsibility of the management to gauge its short-term and long-term impact on the women's performance, commitment, involvement as well as motivational levels. In today's dynamic business environment, women are expected to welcome and accept constant change while maintaining their performance, efficiency and creativity. However, it is easily said than done and nothing is further from the truth. Change is inevitable, but it also brings a lot of stress, exhaustion, and apprehension on the part of the women, who often feel overwhelmed by change at the workplace (Bligh, 2006).

Organizations and their women are constantly faced and challenged by change. In this respect, the workforce requires constant support and motivation from their managers and supervisors. In this capacity, these managers must act as leaders and mentors, facilitating change and easing the concerns of the women about the impending organizational changes (Marquis and Tilcsik, 2013).

Often changes in organizational culture lead to a diminishing impact on the motivation and performance of women, especially when change is not handled and managed properly and with care. Change management refers to defining and developing new cultural values, norms, attitudes and behaviors to introduce new ways and means of doing things. It also brings everyone on board to overcome any resistance to change and explains to the women who will be affected by these changes that it is meant to cater to their own needs, requirements, growth and development (Ravasi and Schultz, 2006). It also facilitates the smooth transition from one organizational culture to the next by thoroughly planning and implementing all the crucial steps and aspects of change management (Zhang, 2009).

While organizational culture change may be by caused several factors, such as marketplace shifts, international expansion, change in organizational strategy, technological improvements, or increased competition, mergers and acquisitions remain the most compelling and frequent reason for the change in organizational culture and its impact on women's motivation.

A merger is defined as when two or more companies or businesses combine to form a new business entity, while an acquisition is when one company buys another and no new company is formed. In this respect, organizations go for corporate mergers and acquisitions for different reasons. This range from purely financial, to strategic, political, etc. Similarly, hightech companies or research and development organizations often merge to pool resources in terms of talent, skill and expertise and better serve the common target markets. Moreover, some organizations opt for mergers or acquisitions to reduce competition, production costs or enhance economic efficiency (Goetsch and Davis, 2014).

While they merge with other businesses, companies often lose their original character and culture, resulting in decreased morale, commitment and motivation on the part of the women. Several factors and elements can lead to an unsuccessful culture transformation and change 
management in the organizations. This becomes a full-fledged issue when managers fail to understand and determine the crucial role of organizational culture in managing change and women's motivation (Jackson, 2002). This is especially a vulnerable and sensitive issue, nonetheless because culture is not exactly tangible or visible clearly. When companies merge or acquire each other, one of the three things can happen:

- An entirely new culture appears;

- The culture of the dominating organization absorbs and overrides that of the other company or business;

- The new culture emerging from the merger includes the best of both cultures

In each of the three situations above, the precise impact of the change in organizational culture will have differing effects on the motivation of women. In the first instance, the new culture may or may not be acceptable to the women of both organizations, depending on the way the change was handled by the management. If the women were involved in the cultural change, were explained the reasons for the merger or acquisition, and were involved constantly every step of the way, they will be more accepting of the cultural change and will more readily adapt to the new organizational culture. In the second scenario, on the other hand, the women of the second, subordinate organization will feel discontent and disillusionment, which will lead to a sharp decline in their performance, efficiency and motivation (Noe et al., 2014). They will be less satisfied with their jobs and career and will perform poorly following this kind of cultural change as a result of the respective merger or acquisition. In the third example, the two cultures merge or change nicely, and attempt the combined management strives for a win-win situation. The women will be able to realize that the positive changes in the way they do things now are meant for their good, for their career development and to meet their own needs and requirements in a better way. Hence, it is expected that the willingness to change on the part of the women is adequately captured in the third scenario.

The Resistance to Change Model will clarify and crystallize the issue of organizational culture change and its effect on women's motivation. Most often when the management decides to transform and change the culture of the organization, women are seldom involved and there is little participation in the decision on their part. This will ultimately lead to women's dissatisfaction and resistance to change, which will, in turn, influence their motivational levels negatively. Hence, when the management preoccupies itself with the implementation of change rather than managing the process of change and bringing the women onboard, the cultural change efforts will fail and the women's morale and motivation will diminish.

\section{Material and Methods}

\subsection{Research Design and Approach}

The proposed research is qualitative, which means the research will be aimed at determining the underlying meaning of the opinions, reasons, and insights into the issue or problem at hand, involving non-numerical, qualitative data. In this connection, the current research project will involve understanding and evaluating the effect of organizational change at KElectric on the women's of the organization, and will hence employ a cross-sectional research design, a combination of secondary and primary research using a semi-structured interview 
technique and the utilization of a thematic analysis for analyzing the data set and providing meaning conclusions.

\subsection{Nature of the Research Project}

The research to be undertaken will be a causal research approach that will be aimed at understanding a cause-and-effect relationship. In this respect, the independent variable in the current study will be the organizational cultural change, while the dependent variable will be women's motivational levels at the organization.

\subsection{Data Collection Tool}

Although several useful tools and techniques are available while conducting qualitative research, the interview technique will prove most appropriate for the causal nature of the research project at hand. In this connection, a semi-structured, face-to-face interview technique will be utilized for this research study, as it will help find detailed and meaningful insights into the issue of the impact of organizational culture change on women's motivation.

\subsection{Population}

The research population refers to the larger or universal population with common attributes and that is the target of the research study. The research population for the current study includes the entire workforce employed at K-Electric, including managers, supervisors, front line women's, clerical staff as well as janitorial staff.

\subsection{Research Sample, Sample Size and Sampling Technique}

Due to the impracticality and impossibility of including the entire research population in the study, a sample is usually drawn from the population. A research sample, hence, is a subset of the total population that is representative of the population in terms of attributes, opinions, beliefs, attitudes, or behaviors. The sampling technique that will be employed to select a sample will be the stratified random sampling technique, which will entail dividing the universal population into several strata from which the sample members will be selected on a random basis from each stratum. The sample size will include 200 participants or respondents for interview sessions.

\subsection{Data Collection Tool: Primary Research}

As already mentioned, a semi-structured interview technique will be employed for primary research. The interview will include close-ended questions to encourage valuable new insights into the issue at hand while keeping some control on the session on the sessions in terms of time and budget limitations.

\subsection{Secondary Data Collection}

While the interviews will serve as the primary collection tool, the secondary collection will be based on a thorough literature review conducted on existing academic research studies available on the topic, including journal articles, news articles, online databases, textbooks, reference books, as well as websites, blogs and other web-based sources. 


\section{Findings and Analysis}

\subsection{Reliability Test}

It is the beginning of SPSS data processing. Data reliability will be tested to see if the data is sufficiently accurate to be analyzed. When the reliability of the data is less than 0.6 , then the obtained data is considered to be inaccurate according to the statistical criteria. However, the data will be considered to be reliable when the computed value is either 0.6 or above 0.6 . The reliability test has also been used in this study, and the results obtained are given below.

\section{Table 1: Reliability Test}

\section{Reliability Statistics}

\begin{tabular}{|c|r|}
\hline $\begin{array}{c}\text { Cronbach's } \\
\text { Alpha }\end{array}$ & N of ltems \\
\hline .893 & 17 \\
\hline
\end{tabular}

The collection of the data is thus accurate and further statistical research can be done on it as the value of Cronbach's Alpha is calculated at 0.893 .

Table 2: Demographic Profile

\begin{tabular}{|ll|r|r|r|r|}
\multicolumn{7}{|c|}{ Gender } \\
\hline & & & & Cumulative \\
& & Frequency & Percent & Valid Percent & Percent \\
\hline Valid & male & 130 & 65.0 & 65.0 & 65.0 \\
& female & 70 & 35.0 & 35.0 & 100.0 \\
& Total & 200 & 100.0 & 100.0 & \\
\hline
\end{tabular}

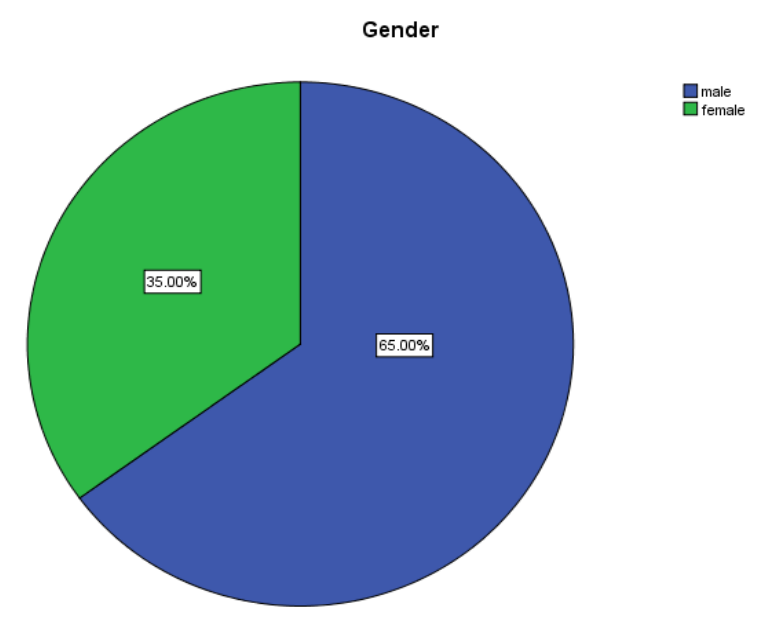

Figure 1: Pie Chart 1 (Gender) 
Following the table above, it is recognized that the majority of women are male whereas only $35 \%$ are females who answered the questions.

\section{Table 3: Position}

\section{Position}

\begin{tabular}{|c|c|c|c|c|c|}
\hline & & Frequency & Percent & Valid Percent & $\begin{array}{c}\text { Cumulative } \\
\text { Percent }\end{array}$ \\
\hline \multirow[t]{5}{*}{ Valid } & Department Manager & 109 & 54.5 & 54.5 & 54.5 \\
\hline & Agents & 59 & 29.5 & 29.5 & 84.0 \\
\hline & Lower ManageriExecutive & 24 & 12.0 & 12.0 & 96.0 \\
\hline & Lower Stafficlerks & 8 & 4.0 & 4.0 & 100.0 \\
\hline & Total & 200 & 100.0 & 100.0 & \\
\hline
\end{tabular}

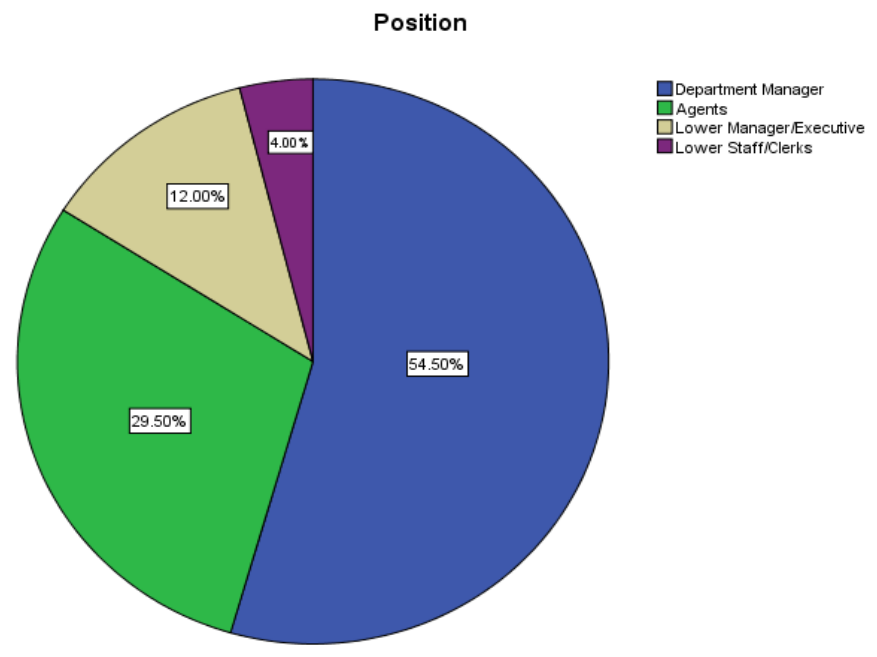

Figur 2: Pie Chart 2 (Position)

The above graph indicates that the majority of women are departmental management personnel, with $29.5 \%$ officers, $12 \%$ lower managers/managers and $4 \%$ lower staff/clerks.

Table 4: Service with organization

Service with organization

\begin{tabular}{|c|c|c|c|c|c|}
\hline & & Frequency & Percent & Valid Percent & $\begin{array}{c}\text { Cumulative } \\
\text { Percent }\end{array}$ \\
\hline \multirow[t]{5}{*}{ Valid } & Less than 6 months & 80 & 40.0 & 40.0 & 40.0 \\
\hline & $6-12$ months & 89 & 44.5 & 44.5 & 84.5 \\
\hline & $1-2$ years & 16 & 8.0 & 8.0 & 92.5 \\
\hline & More than 2 years & 15 & 7.5 & 7.5 & 100.0 \\
\hline & Total & 200 & 100.0 & 100.0 & \\
\hline
\end{tabular}




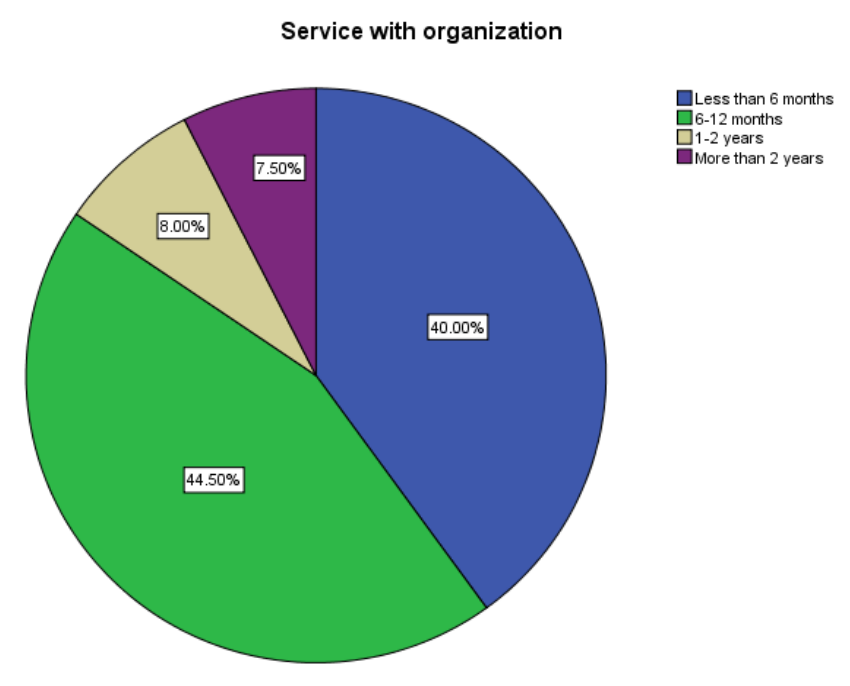

Figure 3: Pie Chart (Service with Organization)

In the following table and chart, the majority of workers had 6-12 months of experience; $40 \%$ of them had less than 6 months, $8 \%$ of them had $1-2$ years and $7.5 \%$ of them had more than 2 years experience.

\section{Table 5: Educational Qualification}

\section{Educational qualification}

\begin{tabular}{|c|c|c|c|c|c|}
\hline & & Frequency & Percent & Valid Percent & $\begin{array}{c}\text { Cumulative } \\
\text { Percent }\end{array}$ \\
\hline \multirow[t]{4}{*}{ Valid } & Secondary school & 55 & 27.5 & 27.5 & 27.5 \\
\hline & Degreeidiploma & 129 & 64.5 & 64.5 & 92.0 \\
\hline & Post-graduation & 16 & 8.0 & 8.0 & 100.0 \\
\hline & Total & 200 & 100.0 & 100.0 & \\
\hline
\end{tabular}

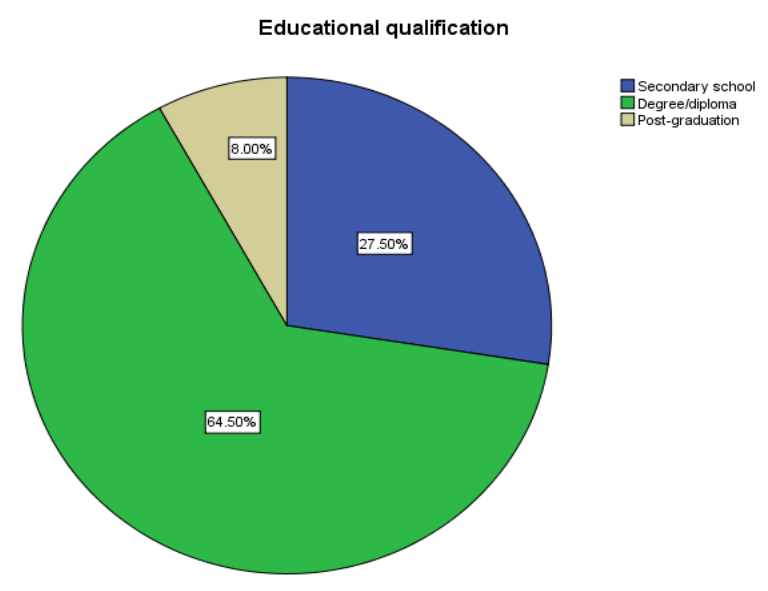

Figure 4: Pie Chart 3 (Educational Qualification) 
According to the pie chart above, it is identified that majority, $\mathrm{k}$; prof individuals had degree/diploma qualification, $27.5 \%$ had secondary school and only $8 \%$ of them had postgraduation degrees.

\subsection{Regression Analysis}

The research focuses on the identification and understanding of causes and elements that directly or indirectly influence K-electric women's motivation. One of the factors found by the researcher is the change in corporate culture, based on the responses received. To clarify the effect and its relationship with the dependent variable, the regression test was applied and the results collected below are inspiring women's.

\section{Hypothesis 1}

H1: There is a significant impact of organizational culture change on women's motivation

Table 6: Model Summary

Model Summary
\begin{tabular}{|l|l|r|r|r|}
\hline Madel & $\mathrm{R}$ & $\mathrm{R}$ Square & $\begin{array}{c}\text { Adjusted R } \\
\text { Square }\end{array}$ & $\begin{array}{c}\text { Std. Error of } \\
\text { the Estimate }\end{array}$ \\
\hline 1 & $.649^{\mathrm{a}}$ & .122 & .117 & .59515 \\
\hline
\end{tabular}

a. Predictors: (Constant), organizational_culture_change

\subsection{Model Summary}

The Model Summary is a key table obtained via the regression test. This table takes into account the value of $\mathrm{R}$ square as it measures the strength of the relationship between the variables and shows this power. Here if $\mathrm{R}$ square values are measured between 0.2 and 0.4 ; $20 \%$ and $40 \%$, the relationship is assumed to be moderate. If the value is less than 20 percent, the ratio to the weaker end and if it occurs above 0.6 or 60 percent, the relationship or effect of separate variables is called high on the dependent variables.

This factor is measured in the latest research as 0.649 ; this is approximately $66 \%$. Therefore, dependent variables have a heavy effect on the dependent variable; this is K-electric motivation for women.

Table 7: Coefficient

\begin{tabular}{|c|c|c|c|c|c|c|}
\hline \multicolumn{7}{|c|}{ Coefficients $^{\bar{a}}$} \\
\hline \multirow{2}{*}{\multicolumn{2}{|c|}{ Madel }} & \multicolumn{2}{|c|}{ Unstandardized Coefficients } & \multirow{2}{*}{$\begin{array}{c}\begin{array}{c}\text { Standardized } \\
\text { Coefficients }\end{array} \\
\text { Beta }\end{array}$} & \multirow[b]{2}{*}{$t$} & \multirow[b]{2}{*}{ Siq. } \\
\hline & & $\mathrm{B}$ & Std. Error & & & \\
\hline 1 & (Constant) & 1.373 & .116 & & 11.845 & .000 \\
\hline & $\begin{array}{l}\text { organizational_culture_ } \\
\text { change }\end{array}$ & .282 & .054 & .349 & 5.236 & .000 \\
\hline
\end{tabular}

a. Dependent Variable: Emplovee motivation 
Values from the table of coefficients are often considered to be extremely significant. It is because the sig meaning in it shows whether or not the alternative hypothesis is accepted. This shows, therefore, that an alternative hypothesis is stated above, which implies that the shift in corporate culture will affect K-electric's motivation. The sig value of 0.000 supports this.

\subsection{Discussion}

Data obtained by the scientist were analyzed using frequency testing and regression testing techniques. The findings of the study showed that the organizational culture element shifts strongly and directly impact K-electric's morale of women. The first goal of the study was to assess whether or not the women's actions and attitudes change in the happiness of their jobs. According to the findings, if all the facilities needed to fulfill them and inspire them are given to workers, their attitude towards their job appears to change positively. The second goal was also accomplished, demonstrating shifts in the corporate culture and its effect on K-electric women's motivation.

Women fanned their best when bosses praised and respected them for their good work. The company is defined as correlating its culture with and as a major factor of the success of kelectric it tests the obvious connexion between its culture and its aims. This work has helped to recognize the transition in corporate culture. This included improved pay, the effective use of your skills, and the conduct of constructive sessions which would improve your skills. This was the third goal achieved. The fourth and final aim was to consider the role of empowered and happy workers in the growth of the company. Research showed that the development of the company means that managers are happy and meet their needs. It can therefore be confirmed that all the aims of this study have been achieved.

\subsection{Interview Analysis}

According to the results above, it can be said that most women are at the position of departmental manager with the educational qualification of degree/diploma. The researcher approached 5 managers of K-electric to know about the impact of organizational culture change on the women's motivation of K-electric. Demographics like their gender, service years and educational qualification were known by the researcher. Analysis of the gathered responses revealed that most of the managers were also male with experience of either 1 year or less than 8 months.

In their answers, K-electric managers stated that the workers they employed had great potential, skills and capacity to achieve the growth goals. $80 \%$ of the approaching managers have verified (Refer to appendix A). According to, the culture of the organization can increase the performance of women's in a large scale that also allows them to be acquainted with the firm's history including the present systems or methods of operation. It can be said that the linkage between organizational culture and women's motivation seeks to recognize other variables that make variations in its performance. In other words, it is identified that Kelectric organizations need supportive culture to aid them to reach their objectives. As an outcome, the evaluation of women's motivation specifically relies upon the factors like compensation, training and development, appraisals, recognition, job security, organizational structure, flexible time system and women's satisfaction. It can be said that managers of the company work together as a team to accomplish results for the organization so that they can 
easily implement a good reward system to encourage their women to do their best and to target the achievements of the organization.

Throughout his study, he said that the company has always grown into the hands of workers from a similar viewpoint. They are the people who expend their time, money, attention, expertise and abilities to meet the goals of the business. In return, they need to appreciate their elderly people and their managers for their good work. It gives them a feeling of pride inside themselves.

The researchers asked about the role of working conditions in the implementation of the change in K-electric's organizational culture. Nearly all the workers responded to the fact that their efficiency appears to be strengthened if they are provided with the necessities at work. In addition, 4 of five managers said that if they have any, they also do everything they can to solve their women's problems and problems. This aspect can be also observed in the research work in which he stated that it is the first and foremost duty of managers is to deal with the problems and issues of women's so that they may feel satisfied and comfortable and contribute maximum towards raising the performance of the business of K-electric (Refer to Appendix A). Managers were asked, on the other hand, if they were interested in recognizing the contradictions and differences that exist between them and the staff. A review of the cumulative responses has shown that 40 percent believe strongly that the differences are often to be reduced and healthy because they contribute to the corporate culture and improvement in the organization (Refer to Appendix A).

\section{Conclusion, Recommendations, and Limitations of the study}

\subsection{Discussion}

According to the data analysis collected from the women's of the selected organization that is K-Electric, the results have been obtained through qualitative means by conducting interviews from the selected respondents, and close-ended questionnaires were filled by the women's to obtain the quantitative data, for optimal research findings and analysis. The obtained results uncovered an important point that the independent variable that is organizational cultural change has a strong influence on the dependent variable that is women's motivation in K-electric. From the analysis and inferences of the data, it has been depicted that the overall research aim and objectives of the study have been achieved successfully. The main purpose of this research is "To investigate the organizational culture change and its effect on women's motivation: a case of K-electric".

The first and foremost objective of this study is to assess the extent to which women's attitudes towards work change when they are satisfied. The objective has been achieved by asking the women regarding their attitudes and behaviors whenever they are satisfied and dissatisfied with their work. Moreover, they were asked about the incentive programs, engagement and participation in organizational activities and overall analysis revealed that all these programs affect the motivation level to a great extent. In the view of Marshak (2005), the positive reinforcement in the behavior of women is of utmost importance, as these tools help to modify the behavior of women, and increase their loyalty and commitment, thus, they support the overall change in the organization.

The second objective is to identify how organizational culture change could influence the women's motivation for K-Electric. The second objective has been accomplished by asking 
questions such as whether women feel more inclined towards organization whenever they receive in return the support from their managers and organization. Women's said that they feel an urge and motivation to perform at an optimal level, to receive appreciation and recognition from their managers. According to Dean (2009), the women in the organization do not only want the extrinsic level of motivation, but also an intrinsic motivation. The less motivation and support can likely influence the women to resist the change and transformation, hence, hinders the growth and progress of the organization.

The third objective is to investigate the key motivating factors for K-Electric women. This objective has been achieved by identifying the main motivating factors that are directly affecting women. These factors include promotion, career growth and advancement, training and development, appraisals and other programs are key motivating factors. Furthermore, the last objective is to review the role of motivated staff towards the success of K-electric. The analysis has been conducted in this regard for achieving the stated objective in terms of the strategies of K-electric to manage and motivate the human resources, and they revealed that their main area of concern and focus is to fulfill the personal and professional needs of all the women's and making sure that their objectives and goals must be aligned with the overall organizational goals and strategies. As per Marshak (2005), the women's maximum level of satisfaction and motivation is very significant to achieve not only short term organizational goals and objectives but also long term goals and objectives. Furthermore, whenever, managers demonstrate care and support to the people in terms of achieving their personal goals and objectives, they also in return perform at their best, as achievement of professional goals requires acquiring the skills and expertise. Hence, all these efforts ultimately resulted in organizational growth and progress.

\subsection{Conclusion}

Hence, in the end, it can be successfully concluded that lucrative businesses essentially provide incentives not only monetary but also non-monetary, to fully ensure the intrinsic level of women's motivation as well as the extrinsic level of motivation in the organization. Moreover, the organizational culture change requires a high level of women's motivation, and for this, having a higher level of women's satisfaction with the women's is of utmost importance. Hence, at K-Electric, women are being provided with financial as well as emotional support to a great extent, so that they can fully achieve their personal as well as professional goals and objectives. Furthermore, the research study also identified the importance of having motivated women's in the organization, especially during the cultural change management process. Hence, it can be concluded that managers must understand that management of women's should be done in a way that can potentially reduce their resistance level towards change, make them more adaptable and flexible to accept the cultural change, and unleash their maximum level of potential so that they can do maximum out of minimum.

\subsection{Research Recommendation}

After the detailed analysis of the obtained data, the research study has revealed some of the crucial areas that need further room for improvement to ensure the success of the K-Electric in the long run. The set of recommendations are stated as follows:

It is highly recommended for the management of K-Electric to manage the cultural change in the organization and enhance the motivation of the women's to initiate formal programs of 
women's engagement, to encourage their level of participation in the organization, moreover, take into consideration the components of cultural norms and objectives of each individual in the organization so that a common organizational culture can be formed and followed by the women's.

In addition to this, it is also suggested to take into account the needs and requirements of every individual in the organization, before developing the incentive goals and programs for the women's, along with this, conduct a proper survey to identify in detail, the types and kinds of incentives, that can, directly and indirectly, motivate the women's of the K-electric, and this survey should be conducted on either semi-annual basis or annual basis.

\subsection{Research Limitations}

There were some of the limitations of the research, which are stated as follows:

The study has been conducted over a limited time frame; hence, it is difficult to generalize the overall findings.

The research study is company-specific. There is only one company that has been chosen for this study that is K-electric, hence, all the analysis and results are limited to the only chosen organization.

Furthermore, the geographical context that has been selected and in which the company formally exists is in Pakistan, and the chosen city is Karachi. Thus, findings cannot be generalized in any way.

\subsection{Future Implications}

This research study has successful future implications for other organizations working in the same industry or sector. It can truly help the policy makers and top management of various organizations to take into consideration the impact of organizational cultural change, and the importance of women's motivation to achieve success and growth. Moreover, researchers in the future can also take benefit from this research, to develop the strategies and standard benchmark, that can fully suggest them to design proper change management processes in the organization and embedded goal of maximum women's satisfaction and motivation.

\section{References}

Abonam, N.D. (2011) The Role of Motivation on Women's Performance in the Public Sector: A Case Study of the University for Development Studies- WA Campus.

Adkins, B.; (2004). Firm or subgroup culture: Where does fitting in matter most?. Journal of Organizational Behavior 25 (8): 969-978.

Anderson, D. \& Anderson, L.A. (2001). Beyond Change Management: Advanced Strategies for Today's Transformational Leaders. San Francisco: Jossey-Bass/Pfeiffer.

Black, R. J. (2003). Organizational Culture: Creating the Influence Needed for Strategic Success, London UK, ISBN 1-58112-211-X.

Bligh, M. C., (2006). Surviving Post-merger 'Culture Clash': Can Cultural Leadership Lessen the Casualties?. Leadership 2: 395-426.

Dean, C. (2009). RIMER Managing Successful Change. Australia: Uniforte Pty Ltd. 
Dysvik, A. and Kuvaas, B. (2010). Exploring the relative and combined influence of masteryapproach goals and work intrinsic motivation on women's turnover intention. Personnel Review. 39 (5), pp.622 - 638.

Epstein, M. J., \& Buhovac, A. R. (2014). Making sustainability work: Best practices in managing and measuring corporate social, environmental, and economic impacts. Berrett-Koehler Publishers.

Fullan, M. (2011). The six secrets of change: What the best leaders do to help their organizations survive and thrive. John Wiley \& Sons.

Goetsch, D. L., \& Davis, S. B. (2014). Quality management for organizational excellence. Pearson.

Hartnell, C. A., Ou, A. Y., \& Kinicki, A. (2011). Organizational Culture and Organizational Effectiveness: A Meta-Analytic Investigation of the Competing Values Framework's Theoretical Suppositions. Journal of Applied Psychology.

Hartog, D.N.D., Boselie, P. and Paauwe, J. (2004) Performance Management: A Model and Research Agenda. Erasmus Research Institute of Management (ERIM).

Jackson, T. (2002). The management of people across cultures: Valuing people differently. Human Resource Management, 41: 455-475.

Judge, T.A., Heller, D. and Mount, M. K. (2002). Five-factor model of personality and job satisfaction: A meta-analysis. Journal of Applied Psychology, 87: 530-541.

Marquis, C., Tilcsik, A., (2013). Imprinting: Toward A Multilevel Theory. Academy of Management Annals: 193-243.

Marshak, R. J. (2005). Contemporary Challenges to the Philosophy and Practice of Organization Development". In Bradford, David L.; Burke, W. Warner. Reinventing Organization Development: New Approaches to Change in Organizations. pp. 1942. ISBN 978-0-7879-8159-4.

Noe, R. A., Wilk, S. L., Mullen, E. J., \& Wanek, J. E. (2014). Women's Development: Issues in Construct Definition and Investigation of antecedents. Improving Training Effectiveness in WorkOrganizations, ed. JK Ford, SJW Kozlowski, K. Kraiger, E. Salas, and MS Teachout (Mahwah, NJ: Lawrence Erlbaum, 1997), 153-89.

Phillips, J. R. (1983). Enhancing the effectiveness of organizational change management. Human Resource Management 22 (1-2): 183-99.

Ravasi, D.; Schultz, M. (2006). Responding to organizational identity threats: Exploring the role of organizational culture. Academy of Management Journal 49 (3): 433-458.

Robbins, S., Judge, T. A., Millett, B., \& Boyle, M. (2013). Organizational behavior. Pearson Higher Education AU.

Zhang, X., (2009). Values, Expectations, Ad Hoc Rules, and Culture Emergence in International Cross Cultural Management Contexts. New York: Nova Science Publishers. 